\title{
Psychiatry and the law
}

\section{Diminished responsibility in Scotland: new technology and old legal definitions}

\author{
Mary Stewart, Consultant Psychiatrist, Whyteman's Brae, Victoria Hospital, \\ Kirkcaldy KY2 5AH
}

The following recent murder trial at a Scottish High Court raises some points of interest to all UK psychiatrists in relation to the use of brain imaging test results as psychiatric evidence and their relevance to the question of diminished responsibility. It should be noted that in Scotland diminished responsibility has a much narrower scope than that encountered in the England and Wales (Chiswick, 1991) and is dependent upon the presence of a "mental disorder or a mental illness or disease" (Connelly v HMA 1990).

\section{Evidence related to the murder}

The case held before Lord Coulsfield concerned $\mathrm{Mr}$ W, a 58-year-old former electroplater, unable to work for three years because of back injury, who was accused of the murder of his second wife. Both were married for the second time and each had children from their first marriage. The relationship was good until four years ago when frequent arguments started.

After one of their arguments in October $1990 \mathrm{Mr}$ W separated from his wife and went to live with his children in England. In May the following year it was agreed that he could return to live with his wife on condition that ownership of the house was signed over to Mrs W on her insistence. A few days after his return his wife disclosed that she had a lover, which he later told police was a surprise to him. On the night of the offence, about ten days later, $\mathrm{Mr} \mathrm{W}$ went to a bingo night at a local pub. On his return an argument started and was overheard by neighbours. According to Mr W's testimony, his wife had phoned her daughter in the past during such arguments and this had several times led to his arrest, in his view unjustly, on breach of the peace charges. On this occasion he decided to cut the telephone wire with a kitchen knife. His evidence of what he subsequently did with the knife was contradictory, but the argument continued and he eventually used the knife to stab his wife to death. He then walked to a local police station to report what he had done.
One of the witnesses, the deceased's daughter, whose obvious dislike of $\mathrm{Mr} \mathrm{W}$ was pointed out by the defence solicitor, claimed that $\mathrm{Mr} \mathrm{W}$ had been aware of his wife's lover prior to his return but had agreed to live under the same roof without resuming marital relations. Mr W's daughter, on the other hand, said he had returned expecting to resume the marriage. She described overhearing Mrs W shouting at her husband when she telephoned to speak to Mr W some days prior to the murder. The accused's former solicitor (who dealt with the separation and transfer of property) described a distressed phone call from $\mathrm{Mr} \mathrm{W}$ earlier on the day of the offence and said she had been concerned enough by his frame of mind to give him the telephone number of the Samaritans.

The facts of the case were not in dispute since $\mathbf{M r}$ W had admitted killing his wife; however, there was disagreement about how far he was responsible for his actions which emerged during the psychiatric evidence.

\section{Psychiatric evidence}

There was one psychiatrist for the defence and two for the crown. The defence psychiatrist (Dr A) felt there were grounds for a plea of diminished responsibility. He noted that there was a history of spinal osteoarthritis and of dizzy spells. He emphasised also that the offence was out of character for $\mathrm{Mr} \mathrm{W}$ and occurred at a time of emotional stress. He found no psychiatric illness or disorder at clinical examination other than an appropriate grief reaction, but felt that the behaviour at the time of the offence might in itself indicate mental disorder since it was out of character, being impulsive, explosive and frenzied.

He had arranged investigations which included standard EEG and recordings of evoked responses to sensory signals and also a SPECT (single photon emission computerised tomography) scan. These tests showed "significant abnormalities of brain functioning compatible with patchy impairment of blood flow to certain parts of the cerebral cortex". 
The court was told that the results indicated widespread disturbance of brain functioning which was likely to have impaired impulse control at the time of the offence. The patient probably had very early vascular dementia and had decompensated under stress. In due course symptoms of psychiatric illness would become evident on psychiatric examination as the condition progressed. Dr A concluded that the offence was carried out during an abnormality of mind not amounting to insanity but in which responsibility was diminished.

Under cross-examination he agreed that his view presupposed that the patient suddenly snapped and grabbed the knife. He was asked to read out the parts of Mr W's statement to police which referred to the location of the knife just before the murder. These sections were in fact contradictory and the possibility of a planned attack remained.

Both crown psychiatrists took the view that there was no clinical evidence of mental disorder and no psychiatric grounds for a plea of diminished responsibility. It was noted that $\mathrm{Mr} \mathrm{W}$ was appropriately concerned and preoccupied by the circumstances in which he found himself

The first crown psychiatrist (Dr B) was asked in detail about the evidence presented by the defence. He stated that, in the absence of clinical evidence of mental disorder on detailed psychiatric examination, the test results were insufficient grounds to raise a plea of diminished responsibility, which is a legal concept. He did not dispute the findings of the tests but disputed their clinical importance and validity in the absence of abnormalities on clinical examination. He admitted under cross-examination that he had no expertise in the neuropsychological tests undertaken by the defence psychiatrist, but was doubtful if a firm link could be made between abnormalities on the SPECT scan etc and the hypothesis of impaired impulse control, where there was no other evidence of the latter either in the clinical history or the examination. The role of the psychiatrist in addressing the question of diminished responsibility was, he felt, to find evidence of mental disorder, not to find an explanation for behaviour. As a result of the marital difficulties Mr W may have been in severe emotional distress but there was no evidence of mental disorder. The latter could not be inferred solely from his behaviour at the time of the offence.

In taking this view Dr B believed that, in order to raise a plea of diminished responsibility, a mental disorder is defined as any psychiatric disorder which would require admission to a mental hospital under the Mental Health (Scotland) Act. There is a qualitative difference from normal experience.

The second crown psychiatrist (Dr C) was broadly in agreement with the first, stating that there was no clinical evidence of mental disorder which could raise a plea of diminished responsibility. The psychiatric evidence formed only part of the trial, which lasted one week, but was crucial to the defence plea. In the end the jury found the defendant guilty of murder by a majority and did not accept the plea of diminished responsibility.

\section{Discussion}

This murder case was not unusual in that it arose out of domestic violence associated with alcohol intake. What is interesting is that a medical witness submitted evidence derived from brain imaging technology to demonstrate clinical abnormalities not found by ordinary clinical examination. The court was faced with the bewildering task of weighing up two different approaches to diagnosis from the expert psychiatric witnesses, in order to determine if mental disorder and therefore diminished responsibility, was present. There may well be similar cases in the future and our legal colleagues will seek to inform themselves about such technology. Indeed the media is already alert to the issues arising from the presentation of results of brain scanning tests in court (Matthews, 1992).

Diminished responsibility, a Scottish invention, first appeared in 1867, in the case of Alexander Dingwall. Under Scottish law it is one of several legal categories which can reduce a charge of murder to culpable homicide (equivalent to manslaughter in England and Wales). Those readers familiar with the 1957 Homicide Act of England and Wales will recall that section 2 allows the statutory defence of diminished responsibility where the accused is suffering from "abnormality of mind". Lord Parker's definition in the case of Byrne 1960 has meant that in England and Wales abnormality of mind is

"wide enough to cover the mind's activities in all its aspects, not only the perception of physical acts \& matters, and the ability to form a rational judgement whether an act is right or wrong, but also the ability to exercise will power to control physical acts in accordance with that rational judgement."*

The defence of diminished responsibility therefore applies to a wider range of situations than is the case in Scotland.

In cases of the type described above there are, however, in Scottish law several 'bench-mark cases' relating to diminished responsibility. Both Dr B and Lord Coulsfield referred to the Savage and Connelly cases.

The Lord Alness Criteria (HMA v Savage 1923) continue to be widely quoted. His definition of diminished responsibility is lengthy.

"There must be aberration or weakness of mind; there must be some form of mental unsoundness; there must be a state of mind which is bordering on, though not amounting to insanity; there must be a mind so affected 
that responsibility is diminished from full responsibility to partial responsibility - in other words the prisoner in question must be only partially accountable for his actions. And I think one can see running through the cases that there is implied that there must be some form of mental disease."*

A recent appeal (Connelly v HMA 1990) established that all these criteria must be met, in particular "there is something in the mental condition of the accused which can properly be described as a mental disorder or a mental illness or disease." It had been Dr B's assertion that these criteria had not been met as there must be evidence of actual mental disease. An essential question is whether or not you can claim that findings from the new techniques (in themselves) do, or do not, indicate the presence of mental disease. Dr A took the view that mental disease had been demonstrated, although as with any investigation the results would be open to interpretation.

In advising the jury in the case of $\mathrm{Mr} \mathrm{W}$, the Judge emphasised that diminished responsibility is a question of fact as determined by the jury on the balance of probabilities. It is not enough to establish that mental disease or a defect in brain function is present, it must exhibit itself as mental disease as one would ordinarily understand it. In 1946 Lord JusticeGeneral Normand put it more forcefully (Carracher v HMA), when he said that a trial should not be "subordinated to medical theories." The latter at present seems to apply equally to brain imaging techniques and conclusions drawn from them.

(*Author's italics)

\section{Acknowledgements}

The author gratefully acknowledges the help and support of Dr J. Baird and Dr. D. Chiswick in the preparation of this paper and Professor G. Fenton and Dr D. Rankin for helpful comments.

\section{References}

Chiswick, D. (1991) Chapter IV:10. Criminal Responsibility in Scotland. In Principles and Practice of Forensic Psychiatry, p 313-318. Edinburgh: Churchill Livingstone.

GANE, C. H. W. \& STODDARD, C. N. (1988) A Casebook on Scottish Criminal Law. Edinburgh: Green.

MatTHEws, R. (1992) It was the lobes, m'lud. Sunday Telegraph Review, Aug. 9, viii.

\section{Cases referred to:}

R v Byrne 1960 Criminal Appeal Reports 44 p 246-255. HM Advocate v Savage 1923 (Lord Justice-Clerk Alness) JC 49; 1923 Scots Law Times p 659-661.

Carracher v HMA 1946 (Appeal) Lord Justice-General Normand JC108; 1946 Scots Law Times p 225-227.

Connelly v HMA 1990 (Appeal) Lord Justice-General Hope Scottish Criminal Case Reports p 504-510.

\section{Reduced subscriptions}

A reduced subscription rate for the International Journal of Psychoanalysis for 1994 is available to College Members at $£ 77$. Interested Members should send a cheque made payable to the Royal College of Psychiatrists to Mrs Jean Wales at the College by 1 October 1993. 